\title{
Notas para discussão quanto à implementação de programas de governo: Em foco o Programa Nacional do Livro Didático*
}

Eloisa de Mattos Höfling**

RESUMO: A concepção de políticas públicas sociais, mesmo comportando diferentes ênfases, deve trazer implícitos os princípios de maior democratização nas esferas de decisão e maior distribuição de benefícios sociais à população focalizada. O Programa Nacional do Livro Didático - PNLD, como um programa de governo no interior da política educacional, também deve ser analisado à luz destes parâmetros. A participação historicamente concentrada de reduzido número de grupos editoriais privados no processo decisório referente à implementação do PNLD, coloca em questão tanto os objetivos como o alcance de uma política pública de corte social.

Palavras-chave: Políticas sociais, política educacional, programa de governo, livro didático

Inicialmente quero explicitar quais serão meus parâmetros para analisar o Programa Nacional do Livro Didático (PNLD) neste texto.

Entendo o PNLD como uma estratégia de apoio à política educacional implementada pelo Estado brasileiro com a perspectiva de suprir uma demanda que adquire caráter obrigatório com a Constituição de 1988: "O dever do Estado com a educação será efetivado mediante a garantia de (...) VII - atendimento ao educando no ensino fundamental, através de progra-

\footnotetext{
* Texto originalmente apresentado no XXII Encontro Anual da Associação Nacional de Pós-graduação e Pesquisa em Ciências Sociais - ANPOCS. Caxambu, outubro de 1998.

** Professora-doutora da Faculdade de Educação, Unicamp.
} 
mas suplementares de material didático-escolar, transporte, alimentação e assistência à saúde" (art. 208).

Assim, fornecer material didático, transporte, merenda escolar e assistência à saúde é uma forma obrigatória de cumprir com o dever do Estado em matéria de educação. O Estado deve assumir o compromisso de garantir o ensino fundamental gratuito e obrigatório e, ao mesmo tempo, o atendimento ao educando, através de programas suplementares. Nesses termos, a natureza dos programas de assistência ao estudante se altera: de caráter assistencial, conjuntural, adquirem pelo preceito constitucional, caráter universalizante, obrigatório, destinados e garantidos a todos aqueles que tem, igualmente, direito ao acesso à educação, pelo menos em termos legais.

A distribuição gratuita de livro didático tradicionalmente vem sendo entendida como uma das funções do Estado no que se refere ao fornecimento do material didático-pedagógico. Mesmo que seja possível uma interpretação mais elástica em relação a essa obrigatoriedade, o próprio governo considera seu empenho na compra e na distribuição gratuita de livros às escolas, como tarefa essencial no atendimento à população escolar. O PNLD é sistematicamente mencionado - e até mesmo politicamente usado - para referendar o nomeado "sucesso" da política educacional brasileira. É um programa de proporções gigantescas ${ }^{1}$, envolvendo em seu planejamento e implementação questões também gigantescas. Para a otimização do PNLD, a descentralização de sua execução tem sido colocada como meta fundamental. Pela amplitude e pelo caráter que assume no âmbito da política educacional, considero o Programa Nacional do Livro Didático uma unidade autônoma para análise, estando nele próprio contidos os contornos de uma política pública de corte social, como é a política educacional. Obviamente isso não significa que sua análise se dê desvinculada de outras estratégias, de outros programas, e muito menos sem considerar a articulação entre a política educacional e outras políticas sociais do Estado brasileiro.

Outro referencial que pretendo explicitar é que desenvolverei neste texto uma análise política, e não de política, em relação ao Programa do Livro Didático e à sua descentralização. Isso significa que estarei mais preocupada com os fatores e atores que determinam uma política de compra e distribuição de milhões de livros didáticos, e menos com os resultados obtidos em relação à cobertura do programa, apesar da reconhecida ligação entre os dois níveis de análise.

Por análise política entendo o estudo das diferentes instâncias que fazem as escolhas em relação a um programa ou mesmo a uma política. Como, por quais atores, são tomadas as decisões no processo de planejamento e 
implementação de uma política pública? Quais os interesses considerados nas decisões quanto a gastos públicos, num programa que envolve recursos consideráveis $^{2}$ ? No caso de políticas públicas sociais, pensadas como ações do Estado visando, em última instância, atingir um padrão de proteção social que expanda a distribuição do bem-estar entre a população, a análise se volta essencialmente para "a aferição do grau de consistência entre os objetivos sociais, os princípios de justiça e, claro, os meios a serem usados" (Figueiredo e Figueiredo 1986, p. 123).

Reconhecendo o movimento positivo em várias iniciativas do MEC em relação ao PNLD, penso que, cada vez com mais intensidade, devemos desenvolver análises políticas dos programas e propostas para educação. Cada vez mais me convenço de que a natureza da reforma da educação necessária não tem prioritariamente raiz administrativa, de gestão, de racionalização de gastos, mas é sim de natureza política: é necessário discutir além de critérios gerenciais de eficiência, de racionalidades institucional e operacional.

A descentralização pretendida em relação ao PNLD é colocada amplamente como uma conquista a ser atingida pelos diferentes níveis de execução da política educacional como um todo. Tem sido considerada indicador de maior qualidade, eficiência e eqüidade na implementação de políticas sociais em geral, e educacional, em particular.

A descentralização apresenta-se como "bandeira" de democratização, de relações menos desiguais e injustas entre os diferentes grupos e setores sociais, entre as diferentes regiões do Brasil, em sua articulação com uma política central. A Constituição de 1988 reflete essa tendência.

Especialmente desde a década de 1980, estudos sobre as desigualdades sociais e regionais no Brasil convergem ao apontar a descentralização como um dos caminhos fundamentais para a alteração de tal quadro. $O$ processo de descentralização, entre outros, é apontado como um avanço na direção de maior democratização e justiça na distribuição dos benefícios sociais para superar as profundas desigualdades acentuadas pelo padrão de proteção social implementado no Brasil pós-64, o qual tem como princípios articuladores: a extrema centralização política e financeira no nível federal das ações sociais do governo; acentuada fragmentação institucional; exclusão da participação social e política da população nos processos de decisão; o princípio de autofinanciamento do investimento social; o princípio da privatização e o uso clientelístico da máquina social (Draibe 1988).

Possivelmente em virtude de uma identificação estreita e apressada entre essas concepções, a descentralização freqüentemente é focalizada como um processo intrinsecamente positivo, por definição mais de- 
mocrático. Apesar de, em princípio, comportar uma ampliação no processo de tomada de decisões, este será certamente condicionado pelos limites institucionais historicamente construídos nos diversos setores das políticas públicas, pela natureza e pelo poder dos atores envolvidos nas decisões, pela participação dos beneficiários dos programas no controle de sua implementação, entre outros fatores.

É importante assinalar também que o conceito de descentralização tem sido usado de maneira generalizada, com pouca referência à heterogeneidade em sua consolidação, com pouca atenção para suas especificidades. Nessa perspectiva, quero reforçar a distinção apontada na literatura recente, a despeito de ênfases diferentes, entre descentralização - muitas vezes confundida com municipalização - e desconcentração. A descentralização, como eu a entendo neste texto, implica alterações efetivas no funcionamento das várias esferas do poder público, envolvendo transferência de poder decisório, de competências, de atribuições e de recursos entre elas. A desconcentração diz respeito à delegação de atribuições no interior de um mesmo nível de governo, para unidades administrativas regionais ou locais, para o exercício de atividades específicas.

Nesses termos, a primeira acepção do termo descentralização, acima, é a que se aproxima da reivindicação histórica de setores progressistas na defesa de uma educação mais democrática e de melhor qualidade ${ }^{3}$.

Na medida em que a descentralização tem sido sistematicamente colocada como objetivo importante para o Programa Nacional do Livro Didático, assim como para todo o sistema educacional, várias questões podem ser levantadas em relação à avaliação política do programa, à implementação da política pública para o livro didático, por exemplo: o formato institucional historicamente construído para execução do PNLD e os atores tradicionalmente envolvidos nas decisões do programa têm contribuído ou não para a descentralização e a implementação de uma estratégia de intervenção mais democratizante, mais voltada para os objetivos próprios de uma política pública social?

Nessa perspectiva, penso que é importante recorrer à história do Programa Nacional do Livro Didático para melhor avaliar as possibilidades de otimização - e descentralização - que podem ser esperadas.

O programa de distribuição de livros - e materiais - didáticos pelo Ministério da Educação passou por várias fases e sua execução, por diferentes órgãos. As origens da relação Estado/livro didático remontam ao ano de 1938, quando o Decreto-Lei ${ }^{\circ} 1006$ instituiu a Comissão Nacional do Livro Didático, estabelecendo condições para produção, importação e utilização do livro didático no Brasil. Por esse decreto foram estabelecidos impedimentos à autorização para edição de livros didáticos e exigências quanto à correção de informação e linguagem. 
Em 1945, o Decreto-Lei no 8460 redimensionou as funções da Comissão Nacional do Livro Didático, centralizando, na esfera federal, o poder de legislar sobre o livro didático. Consolidou-se, pois, a legislação sobre a matéria. O Estado passou, então, a assumir o controle sobre o processo de adoção de livros em todos os estabelecimentos de ensino no território nacional. Gradativamente, tais funções foram se descentralizando, com a criação, em alguns Estados, de Comissões Estaduais do Livro Didático.

A Fundação Nacional de Material Escolar (Fename), criada em outubro de 1967, absorveu os programas desenvolvidos pela extinta Campanha Nacional de Material de Ensino. A Fename tinha como finalidade básica a produção e a distribuição de material didático às instituições escolares, mas, efetivamente, não contava com organização administrativa nem recursos financeiros para desempenhar tal tarefa. Em decorrência dessa situação, em 1970 foi implantado o sistema de co-edição com as editoras nacionais, por

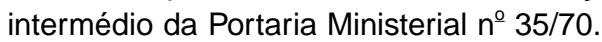

Até 1971, quando foi extinta, a Comissão do Livro Técnico e Didático (Colted), criada em 1966, desempenhou as funções de coordenar e executar as atividades do MEC relacionadas ao aperfeiçoamento do livro didático, à sua produção, edição e distribuição.

A partir de 1972, o Instituto Nacional do Livro (INL), assumiu a responsabilidade de promover e agilizar, em ação conjugada com as editoras, o programa de co-edição de obras didáticas. Criou-se, pois, um programa especial de co-edição, o Programa do Livro Didático (Plid), abrangendo os diferentes níveis de ensino: Programa do Livro Didático para o Ensino Fundamental (Plidef), Programa do Livro Didático para o Ensino Médio (Plidem), Programa do Livro Didático para o Ensino Superior (Plides) e Programa do Livro Didático para o Ensino Supletivo (Plidesu).

Até 1975, o Instituto Nacional do Livro (INL) teve a responsabilidade de promover, juntamente com as editoras, o programa de co-edição. Em 1976, a Fename sofreu modificações em sua estrutura (Decreto 77.107/76), e a ela delegou-se a responsabilidade de desenvolver as atividades dos programas de co-edição de obras didáticas, o que levou ao aumento da tiragem dos livros e à criação de um mercado seguro para as editoras, decorrente do interesse do governo federal em obter boa parte dessa tiragem para distribuí-la gratuitamente às escolas e às bibliotecas das unidades federadas.

Com o sistema de co-edição, de censor oficial dos livros didáticos usados nas escolas brasileiras, o Estado foi assumindo também o papel de financiador desses livros. 
Em abril de 1983, foi criada a Fundação de Assistência ao Estudante (FAE), absorvendo os programas que eram da alçada da Fename e do Inae, órgãos vinculados ao MEC. No mesmo ano, o Programa do Livro Didático (Plid) foi incorporado à FAE. Em 1984, deu-se fim ao sistema de coedição, passando o MEC a ser comprador dos livros produzidos pelas editoras participantes do Plid.

A partir de agosto de 1985, por meio do Decreto-Lei $n^{\circ}$ 91.542, o Programa recebeu a denominação de Programa Nacional do Livro Didático (PNLD), tendo seus objetivos substancialmente ampliados. Estabeleceu-se como meta o atendimento de todos os alunos de primeira a oitava série do primeiro grau das escolas públicas federais, estaduais, territoriais, municipais e comunitárias do país, com prioridade para os componentes básicos Comunicação e Expressão e Matemática.

Em 1996 a FAE é extinta, ficando a cargo do Fundo Nacional de Desenvolvimento da Educação (FNDE) - autarquia federal, vinculada ao MEC, criada em 1968 - a execução do PNLD, com recursos oriundos principalmente do Salário-Educação.

Nos limites deste texto, com o propósito de desenvolver uma avaliação política do PNLD, pretendo focalizar a estreita relação entre Estado e grupos editoriais privados no planejamento e na implementação de um programa considerado essencial ${ }^{4}$ no interior da política pública de educação.

Meu argumento é que a forte presença de setores privados - no caso, os grupos editoriais - na arena de decisão e definição da política pública para o livro didático pode comprometer a natureza, a própria conceituação de uma política social, com contornos mais democratizantes.

No processo decisório relativo a essa política pública, o Estado tem como parceiros representantes do setor privado, inserindo nessas esferas de decisão mecanismos de mercado no mínimo discutíveis quando da definição de gastos de recursos públicos. É impossível supor a ausência de tais grupos editoriais nos rumos do PNLD, uma vez que o MEC não é produtor de obras didáticas. Mas o que é significativo para a discussão é a compra de milhões de livros didáticos, pelo Estado, de um número reduzido de editores, situação que vem se confirmando por um longo período.

Dados levantados por meio de análise de relatórios da FAE (Höfling 1993) e de outras fontes sobre compra de livros didáticos pelo Estado, evidenciam a acentuada centralização da participação de certos grupos editoriais, como se observa nas tabelas a seguir. 
Participação das editoras nas aquisições de

livros pelo MEC PLIDE (1977-1984)

(Em porcentagem)

\begin{tabular}{lccccccccc}
\hline Editora & 1977 & 1978 & 1979 & 1980 & 1981 & 1982 & 1983 & 1984 & Total \\
\hline Brasil & 13 & 11 & 9 & 8 & 11 & 12 & 13 & 13 & 11 \\
FTD & 7 & 8 & 9 & 8 & 15 & 15 & 12 & 15 & 11 \\
Bloch & 0 & 14 & 11 & 11 & 9 & 10 & 7 & 4 & 10 \\
Ática & 6 & 9 & 9 & 9 & 10 & 11 & 10 & 12 & 10 \\
Ibep & 9 & 8 & 8 & 7 & 9 & 9 & 11 & 10 & 9 \\
Abril & 7 & 11 & 6 & 5 & 6 & 6 & 5 & 6 & 7 \\
Caminho Suave & 0 & 2 & 6 & 8 & 9 & 10 & 8 & 7 & 6 \\
Scipione & 5 & 8 & 8 & 5 & 6 & 5 & 5 & 2 & 6 \\
Primor & 10 & 9 & 8 & 6 & 4 & 2 & 3 & 2 & 6 \\
Ao Livro & 9 & 8 & 4 & 6 & 3 & 2 & 1 & 2 & 4 \\
Técnico & 3 & 4 & 5 & 7 & 4 & 2 & 3 & 2 & 4 \\
Lemi & 5 & 1 & 5 & 7 & 1 & 3 & 2 & 1 & 3 \\
Vigília & 2 & 1 & - & 0 & 0 & - & 4 & 10 & 2 \\
Nacional & 12 & 6 & 11 & 12 & 13 & 13 & 15 & 14 & 12 \\
Outros & 100 & 100 & 100 & 100 & 100 & 100 & 100 & 100 & 100 \\
\hline Total & & & & & & & & \\
\hline
\end{tabular}

Fonte: FAE. In Castro, J.A., 1996, p.23.

\section{Participação das editoras nas aquisições de} livros pelo MEC PNLD 1985-1991

(Em porcentagem)

\begin{tabular}{lccccccc}
\hline Editora & 1985 & 1986 & 1987 & 1988 & 1989 & $1990 / 91$ & Total \\
\hline Ática & 11 & 10 & 15 & 17 & 21 & 25 & 17 \\
Brasil & 38 & 23 & 11 & 8 & - & 16 & 17 \\
IBEP & 6 & 17 & 13 & 15 & 16 & 9 & 12 \\
FTD & 9 & 10 & 15 & 12 & 11 & 13 & 12 \\
Nacional & 11 & 17 & 11 & 9 & - & 3 & 8 \\
Saraiva & 8 & 7 & 10 & 9 & 10 & 8 & 8 \\
Scipione & 0 & 3 & 7 & 11 & 9 & 10 & 7 \\
Outros & 16 & 13 & 19 & 19 & 33 & 15 & 18 \\
\hline Total & 100 & 100 & 100 & 100 & 100 & 100 & 100 \\
\hline
\end{tabular}

Fonte: FAE. In Castro, J.A., 1996, p.23.

Considero extremamente significativos os dados obtidos no relatório da FAE em relação ao ano de 1994. Destaco os dados referentes às seis editoras que receberam somas significativas na compra de livros didáticos pelo Estado. 


\begin{tabular}{|l|c|c|}
\hline Editora & Livros adquiridos & Valor $(\mathrm{R} \$)$ \\
\hline FTD & 18.020 .358 & $37.842 .751,80$ \\
\hline Scipione & 11.737 .983 & $23.430 .404,98$ \\
\hline Ática & 8.146 .974 & $18.086 .282,28$ \\
\hline Saraiva & 6.512 .669 & $14.392 .998,49$ \\
\hline Brasil & 5.690 .469 & $9.559 .987,92$ \\
\hline Nacional & 3.086 .487 & $6.049 .496,88$ \\
\hline
\end{tabular}

Fonte: Relatório FAE

Observe-se que, do total gasto pela FAE com aquisições de livros (segundo o relatório, $R \$ 118.704 .786,54$ ), a incrível soma de $R \$ 109.361 .922,85$ foi destinada a seis editoras, entre as 35 concorrentes no total. Ou seja, cerca de $90 \%$ do total de recursos públicos da FAE para compra e distribuição de livros didáticos foi alocado para um grupo que não atinge $20 \%$ do total de editoras inscritas no programa.

Como aponta Castro (1996) em seu trabalho sobre o Processo de Gasto Público (PGP) do PNLD, no início da década de 1990 eram assim definidas as esferas de decisão relativas ao Programa:

(...) d) a organização das decisões sobre os quantitativos a serem adquiridos na DADP (Diretoria de Apoio Didático Pedagógico) foi realizada em reuniões "fechadas" entre os burocratas especialistas da FAE e os representantes das editoras, o que potencializou ainda mais a existência da rede de intermediações e permitiu a manutenção e entrelaçamento das conexões entre a indústria livreira especializada na produção de livros didáticos e os dirigentes da FAE; e) as editoras líderes tinham até um calendário especial para as negociações, eram as primeiras e dispunham de um tempo maior para discutir suas propostas; (...) h) as encomendas, em alguns momentos, foram quase que totalmente pagas antes do recebimento, $50 \%$ no ato da assinatura do contrato, $25 \%$ na entrega de $75 \%$ dos livros encomendados e o restante no dia da entrega total dos livros. (Castro 1996, p. 37)

O Relatório Anual do FNDE referente ao PNDL/98 traz os seguintes dados, dos quais destaco os relativos às seis editoras que mais livros venderam ao Programa Nacional do Livro Didático. 
Demonstrativo de custo por editora: PNLD.MEC/BRASIL.1998

\begin{tabular}{|l|c|c|c|}
\hline Editoras & $\begin{array}{c}\text { Total de } \\
\text { Livros adquiridos }\end{array}$ & Valor (R\$) & Valor (US\$) \\
\hline FTD & 12.022 .521 & $27.880 .471,3$ & 14.751 .571 \\
\hline Scipione & 10.583 .453 & $30.275 .323,57$ & 16.018 .689 \\
\hline Nacional & 7.589 .119 & $24.042 .523,24$ & 12.720 .916 \\
\hline Ática & 6.645 .989 & $14.598 .002,98$ & 7.723 .810 \\
\hline Formato & 6.549 .906 & 11.732 .127 .86 & 6.207 .474 \\
\hline Brasil & 5.461 .242 & $11.694 .156,06$ & 6.187 .384 \\
\hline Sub-total & 48.858 .230 & $120.222 .614,08$ & 63.609 .848 \\
\hline Total & 64.727 .839 & $158.909 .479,84$ & 84.079 .089 \\
\hline
\end{tabular}

Fonte: PNLD/98 - FNDE/MEC - Relatório Final

Obs: Total de editoras participantes: 25 editoras

Essas informações, reforçadas pelos dados das tabelas anteriores, explicitam a posição de determinados grupos editoriais que, com pequenas diferenças de posição ${ }^{5}$, têm interferido nas decisões quanto à aquisição pelo MEC de significativa parcela de sua produção editorial didática.

Pensando nos atores envolvidos em um programa como o PNLD (especialistas e técnicos do MEC, do FNDE, autores de livros didáticos, editores, professores, alunos), seguramente é possível indicar os grupos editoriais privados como o setor mais organizado, com canais estabelecidos, para fazer valer suas posições e seus interesses.

Atuam por meio de vários mecanismos e associações que acompanham sistemática e proximamente as diferentes etapas e os diferentes níveis de decisão implicados no planejamento e na implementação do PNLD.

A Associação Brasileira dos Autores de Livros Educativos (Abrale) não perde oportunidade de se fazer presente como quando torna público "(...) seu apoio às medidas recentemente adotadas (...) que estendem o programa de distribuição gratuita de livros didáticos, beneficiando agora também os estudantes da $5^{\mathrm{a}}$ à $8^{\mathrm{a}}$ séries, das escolas da rede pública de todo o Brasil" (Folha de S. Paulo, 23/5/95).

Recentemente, os editores reagiram enfaticamente contra a avaliação de livros didáticos feita pelas "comissões de especialistas" contratadas 
pelo MEC, que reprovaram e excluíram da lista de compra do ministério vários títulos de diversas editoras ${ }^{6}$. Essas avaliações subsidiam a elaboração do "Guia de Livros Didáticos", a ser distribuído a todos os professores com o objetivo de apoiar suas escolhas em relação ao livro indicado para suas aulas.

Desde 1996 essas comissões têm atuado mais sistematicamente avaliando livros didáticos, e à época da divulgação de seus resultados é possível ler com muita freqüência matérias com títulos como "Editoras vão à Justiça contra o MEC" (Folha de S. Paulo, 21/5/96), "Autores de livros didáticos exigem lista do MEC" (Folha de S. Paulo, 13/1/97), em jornais de grande circulação. Até mesmo pressões diretamente exercidas sobre os pareceristas são relatadas pelos componentes das comissões de avaliação.

Os níveis de participação e intervenção de outros atores envolvidos - ou que deveriam estar - na arena decisória do PNLD não serão aqui abordados, em virtude do recorte do presente texto. O que coloco em discussão aqui é o papel desempenhado por representantes de setores Oprivados na definição de uma estratégia de intervenção (como é o PNLD) no interior de uma política pública social (como é a educação).

A acentuada centralização da participação de um grupo de editoras no PNLD coloca em questão as perspectivas de descentralização do programa. Na medida em que, por sua posição no mercado, dispõem de mecanismos mais eficientes de divulgação, de marketing voltados aos setores compradores e consumidores de seus produtos, esses grupos editoriais alcançam grande poder de penetração e circulação entre seus "clientes". Essa situação, associada a outros fatores, condiciona, em grande medida, a escolha feita pelo professor ${ }^{7}$.

Uma vez que descentralizar um programa de governo deve significar também ampliar os níveis de decisão em seu planejamento e sua implementação, visando essencialmente benefícios sociais, a participação de grupos privados, atuando de forma concentrada, choca-se com os princípios dessa perspectiva mais ampla.

Trazer para o interior da arena decisória de políticas públicas sociais mecanismos - e interesses - próprios de relações mercadológicas deveria ser, no mínimo, motivo de muitas discussões e de análises mais apuradas.

É inegável que os parâmetros para análise, avaliação e mensuração de políticas sociais, de programas que envolvem gastos públicos, obedecem a uma lógica distinta - ao menos deveria ser assim - da que rege a esfera privada, no caso, a de mercado. 
Discutir essas questões, analisar o grau de proximidade entre os objetivos sociais, a descentralização nas esferas de decisão e a alocação dos recursos públicos, na minha perspectiva, é fazer uma avaliação política do Programa Nacional do Livro Didático.

\section{Notas}

1. A distribuição de cerca de 85 milhões de livros didáticos em 1997, coloca o PNLD entre os maiores do mundo.

2. Para a compra dos livros distribuídos em 1997, foram gastos cerca de 203 milhões de reais.

3. Essa relação "dada" entre descentralização e melhoria da qualidade do ensino, insistentemente colocada nos projetos oficiais para a educação, é questionada em interessante texto de Casassus, "Descentralización a la escuela y calidad de la educación: Mitos o realidades?", exposto em seminário promovido pela Fundap em junho de 1998.

4. Tanto em termos da importância conferida ao livro didático pelos órgãos oficiais como estratégia para referendar sua política para a educação, quanto em razão da importância de sua ampla distribuição - quando de boa qualidade - para o processo pedagógico.

5. Considerando-se alterações conjunturais ocorridas nas últimas aquisições, é possível listar as editoras Ática, Brasil, Ibep, FTD, Nacional, Saraiva e Scipione como "parceiras" constantes do MEC na programação do PNLD.

6. Em 1997 as editoras inscreveram 1.159 títulos de $1^{\mathrm{a}}$ a $8^{\mathrm{a}}$ série, dos quais 329 foram reprovados pelas comissões de avaliadores.

7. As pesquisas sobre livro didático sistematicamente apontam a estreita ligação entre catálogos e títulos disponíveis para o professor e as indicações de livros feitas por ele.

Recebido para publicação em Março de 1999.

\section{Notes for discussion about the implementation of government programs: Focusing on the Textbook National Program}

ABSTRACT: The conception of Social Public Policy even with different emphasis should make implicit the principles of larger democratization in the decision spheres and larger distribution of social benefits to the population. The Textbook National Program $P N L D$, as a government program inside the educational politicies also must be analysed based on such parameters. The historically 
concentrated participation of reduced number of editorials private groups in the decision process regarding the PNLD implementation brings to discussion such things: the objectives and the achievement of a social public policy.

\section{Referências Bibliográficas}

DRAIBE, S.M. "O padrão brasileiro de proteção social: Desafios à democratização". Análise \& Conjuntura. Curitiba, 8 (2), fev. 1986, pp. 13-19.

FIGUEIREDO, M.F. e FIGUEIREDO, A.M.C. "Avaliação política e avaliação de políticas: Um quadro de referência teórica”. Análise \& Conjuntura. Belo Horizonte, 1 (3), set./dez. 1986, pp. 107-127.

CASTRO, J.A. "O processo de gasto público do Programa do Livro Didático". Texto para Discussão nํ406. Ipea, mar. 1996.

HÖFLING, E.M. "A FAE e a execução da política educacional”. Tese de doutorado. Campinas: Unicamp, 1993. 